\title{
Effect of different artificial diets on the adults biological attributes of sugarcane stalk borer, Chilo auricilius Dudgeon and evaluation of their costs
}

\author{
M. Soniya Devi ${ }^{1 *}$ and Rabinder Kaur ${ }^{2}$ \\ ${ }^{1}$ Department of Entomology, Punjab Agricultural University, Ludhiana-141004, INDIA \\ ${ }^{2}$ Department of Entomology, Punjab Agricultural University, Ludhiana-141004, INDIA \\ ${ }^{*}$ Corresponding author. E-mail: maimomsoniya@gmail.com
}

Received: October 22, 2014; Revised received: February 17, 2015; Accepted: March 8, 2015

\begin{abstract}
An experiment was conducted to evaluate the effect of different artificial diets on the adult's biological attributes of sugarcane stalk borer (Chilo auricilius Dudgeon) and their costs. Considering the mean values of first and second generation the maximum adult emergence (80.66 and 79.25), longer adult longevity (4.29 and 4.28), highest fecundity (233.45 and 225.98) and viability of egg (216.25 and 208.74) was recorded on diets A and C. Also the sex-ratio on diets $A(M: F:: 1: 1.16)$ and $C(M: F:: 1: 1)$ favoured the emergence of more number of females than males during development. On the basis of the economics also the artificial diets D, C and A (Rs. 48.62, Rs. 48.32, Rs. 103.43, respectively) were found relatively cheaper than the natural food (Rs 166.67). Thus, the overall performance of $C$. auricilius on diets $A$ and $C$ was found comparatively better than the other diets examined. Therefore, it can be used as an alternate diet other than natural diet $E$ (sugarcane) for the mass rearing of $C$. auricilius in the laboratory.
\end{abstract}

Keywords: Artificial diets, Chilo auricilius, Natural diet, Rearing

\section{INTRODUCTION}

Sugarcane (Saccharum officinarum Linnaeus), is one of the main sugar producing crop, which is cultivated in tropical and subtropical areas and holds the most prominent position as the commercial cash crop. As an estimate, sugarcane production is declined by 20 per cent with insect pests and out of these 211 species of insects is reported to attack on sugarcane in India, 18 of which are major and 21 as minor pests (David and Nandgopal, 1986). In tropics, the main cane pests are moth borers. Chilo auricilius Dudgeon (Stalk borer) is one of the most destructive pests of sugarcane in northern India. Number of insecticides has been used by the farmers for the management of this insect, but these methods are proved ineffective (Chaudhary et $a l .$, 1980). The other control measures e.g. cultural and mechanical control methods are cumbersome and usually not followed by the grower. Some attempts have been directed towards the biological methods of control (Misra et al., 1986; Doomra, 1992; Brar et al., 2001 and Shenhmar et al., 2005) for the management of this pest. However, in addition to use of bioagents for the management of sugarcane stalk borer, there are certain areas of research such as production of biopesticides, development of resistant varieties of sugarcane, sex attractants, etc. which are needed to be explored to develop package of integrated pest management for the control of this insect and these studies require rearing of large number of this insect in the laboratory. In the past, attempts have been made to formulate artificial diet for the rearing of C. auricilius in the laboratory (Varma and Avasthy, 1973 and Varma et al.,, 1975). However, the method of preparing this diet is somewhat complex and some of the ingredients are not easily available, and even problems of infection occur while preparing or storing the diets. Therefore, the aim of the present investigation was to evaluate few available artificial diets which have been tried on other lepidopteran insects (Varma et al., 1975; Mehta and David, 1978 and Kanta and Sajjan, 1989) and formulate new alternate diet using indigenous ingredients for the rearing of $C$. auricilius. The present study was, thus, carried out with this consideration in view.

\section{MATERIALS AND METHODS}

The present study was conducted in the Biological Control Laboratory, Department of Entomology, Punjab Agricultural University, Ludhiana during the year 2011-2012. Under this study, four different artificial diets along with natural food (Sugarcane) were selected to rear the stalk borer for two generations in the laboratory at $22-27^{\circ} \mathrm{C}$ and $60-75$ per cent relative humidity $(\mathrm{RH})$. A nucleus culture of $C$. auricilius was maintained on sugarcane cuttings. Larvae or pupae were collected from infested sugarcane fields and the larvae were reared on internodal portion of sugarcane till pupation. The moths emerged were kept in oviposition cages and were provided with water and protinex solution for feeding. The oviposition cages were lined with folded butter paper for egg laying. The newly hatched larvae were used for evaluating the diets. The composition 
and method for the preparation of diets was same as described by Varma et al. (1975), Mehta and David (1978) and Kanta and Sajjan (1989). The finally prepared diet mixture was poured in the battery glass jars $(15 \times 10 \mathrm{~cm})$ up to $2.5 \mathrm{~cm}$ height.

The quantities of ingredients mentioned in table 1 used for preparing diets $\mathrm{A}, \mathrm{B}, \mathrm{C}$ and $\mathrm{D}$ were sufficient for three glass battery jars $(15 \times 10 \mathrm{~cm})$. After pouring the diet mixture in the jars up to $2.5 \mathrm{~cm}$ height, these were covered with pieces of muslin cloth by tying them with rubber bands. These jars were kept at room temperature for 24-48 hours for proper setting of the medium in the jar and evaporation of the excessive moisture adhering to the walls of the jars. $50 \pm 10$ black head stage eggs of $C$. auricilius laid on small pieces of the wax paper were taken from the initial culture and released in each diet jar. In order to reduce the direct contact of the wax paper with the diet and to minimize the chances of fungal growth in diet, the pieces of wax paper containing egg masses were stuck vertically in the diet jar with the help of forceps. In order to facilitate the entry of the larvae into the diet, the diet jars were covered with black paper leaving $2.5 \mathrm{~cm}$ area from below to visualize larvae in the diet. The jars were observed daily to study different parameters. On the onset of emergence in first generation cycle, the pairing of male and female adults from respective diet was done and released in an oviposition jar to start second life cycle (second generation) of $C$. auricilius on the diets. Whenever required or when the diet started drying or get infected, the growing larvae were shifted to freshly prepared artificial diet. For the larvae reared on sugarcane, sugarcane cuttings were replaced with fresh ones on every alternate day till pupation.

The data obtained on different parameters were subjected to statistical analysis using completely randomized design for proper interpretation of results (Cheema and Singh 1990). Critical differences (C.D.) at 5 per cent level of probability were worked out to compare the statistical significance of different diets.

\section{RESULTS AND DISCUSSION}

It was seen that the larvae of $C$. auricilius could not accept the diet $\mathrm{B}$ to complete larval period, showing 100 per cent mortality. Therefore, diet B could not be evaluated for the rearing of $C$. auricilius in the present investigation. The effect of diets $\mathrm{A}, \mathrm{C}, \mathrm{D}$ and $\mathrm{E}$ on various adults biological attributes i.e. adult emergence, fecundity, egg viability, sex ratio and adult longevity of $C$. auricilius were studied for two generations. The economics of diets was also worked out to find the cost of diet in producing viable eggs.

The observations recorded for adult emergence showed that there was no significant difference among diets A, $\mathrm{C}, \mathrm{D}$ and $\mathrm{E}$ for per cent emergence in both first and second generation (Table 2). However, the highest mean per cent moth emergence was found on diet A $(80.66 \%)$ followed by diet $\mathrm{C}(79.25 \%)$ and the lowest mean percent emergence on diet E.

The results in Table 2 showed that the longevity of adult moths obtained from diets $\mathrm{A}, \mathrm{E}$ and $\mathrm{C}$ were found to be similar with one another in first and second generations, being longest life span on diet A (4.45 and 4.14 days, respectively) followed by diet $\mathrm{E}$ ( 4.31 and 4.13 days, respectively) and diet $C$ (4.23 and 3.93 days, respectively). The diet $\mathrm{D}$ was found different from the other three diets, as the life span recorded for moths emerged from this diet during $1^{\text {st }}$ and $2^{\text {nd }}$ generation was shortest being 3.42 and 3.29 days, respectively. The pooled data of longevity for both generations also showed same pattern of influence of diets being longest on diet A (4.29 days) followed by diet $\mathrm{E}$ (4.22 days) and diet C (4.08 days), whereas it was shortest in diet $\mathrm{D}$ i.e. 3.35 days. This proved that artificial diets $\mathrm{A}$ and $\mathrm{C}$ along with natural diet $\mathrm{E}$ were better in regard of longevity of adult moths of $C$. auricilius.

When the moths emerged from different diets were observed for their sex, it was recorded that during first generation, the sex-ratio of male to female in diet $\mathrm{E}$ was $1: 1.1$ which showed that the females outnumbered the males, whereas in other three diets the number of females was less than male number. In the second generation, number of females to males increased in diets $\mathrm{A}$ and $\mathrm{C}$, being the highest in diet $\mathrm{A}(1: 1.16)$ followed by diet $\mathrm{C}(1: 1)$. For artificial diets $\mathrm{D}$ and $\mathrm{E}$, the number of female moths was less than male number i.e. 1: 0.88 and 1:0.9, respectively. These results inferred that the rearing of $C$. auricilius on artificial diets $\mathrm{A}$ and $\mathrm{C}$ favoured the emergence of more female moths than male moths.

Results presented in table 3 showed the maximum average number of eggs laid per female moth was reported in case of diet A (235.12 eggs) in the first generation and was found to be more than those reared on diets C (222.37 eggs), E (219.05 eggs) and D (216.15 eggs) which were on par with one another. In the second generation, fecundity on artificial diets A (231.79 eggs) and C (229.60 eggs) were at par with each other and was found to be higher than those reared on diets E (221.07 eggs) and D (220.58 eggs) which were on par with each other. The mean of the fecundity of $C$. auricilius for two generations was found to be more on diet A (233.45 eggs) followed by diet C (225.98 eggs), whereas mean fecundity was less and on par on diet E (220.06 eggs) and diet D (218.36 eggs). From these results, it was inferred that the diet A followed by diet $\mathrm{C}$ proved superior diets than the diets $\mathrm{D}$ and $\mathrm{E}$ in improving the fecundity of female of C. auricilius.

The data revealed that in first and second generations, higher egg viability was recorded on diet A (217.43 and 215.08) than the other three diets $C$ (207.51 and 209.98), D (202.92 and 205.52) and E (203.12 and 204.12) which were on par with one another. When the data of two generations was pooled, the higher mean 
Table 1. Composition of different artificial diets.

\begin{tabular}{|c|c|c|c|c|}
\hline Ingredients & Diet A & Diet B & Diet C & Diet D \\
\hline French bean $(P$. vulgaris $)$ powder & $100 \mathrm{~g}$ & - & $90 \mathrm{~g}$ & - \\
\hline Bengal gram $(C$. arietinum $)$ powder & - & $15 \mathrm{~g}$ & - & - \\
\hline Green gram flour & - & - & - & $90 \mathrm{~g}$ \\
\hline Wheat flour & - & - & $20 \mathrm{~g}$ & $20 \mathrm{~g}$ \\
\hline Sugarcane (S. officinarum) leaf sheath powder & $50 \mathrm{~g}$ & $24 \mathrm{~g}$ & - & - \\
\hline Casein & $34 \mathrm{~g}$ & $7.5 \mathrm{~g}$ & - & - \\
\hline Yeast & $16 \mathrm{~g}$ & $3 g$ & $5 \mathrm{~g}$ & $5 \mathrm{~g}$ \\
\hline Ascorbic acid & $2 \mathrm{~g}$ & $2.5 \mathrm{~g}$ & $1.7 \mathrm{~g}$ & $1.7 \mathrm{~g}$ \\
\hline Wesson's salt mixture & $5 \mathrm{~g}$ & - & - & - \\
\hline Multivitamins & $8 g$ & - & - & - \\
\hline Vitamin mixture & - & $1.5 \mathrm{~g}$ & - & - \\
\hline Vitamin E & - & - & $0.1 \mathrm{~g}$ & $0.1 \mathrm{~g}$ \\
\hline Hostacycline & - & $1 \mathrm{~g}$ & - & - \\
\hline Sucrose & - & $11.25 \mathrm{~g}$ & - & - \\
\hline Methyl- $p$-hydroxybenzoate & $1 \mathrm{~g}$ & $0.62 \mathrm{~g}$ & $0.8 \mathrm{~g}$ & $0.8 \mathrm{~g}$ \\
\hline Sorbic acid & $0.5 \mathrm{~g}$ & $0.30 \mathrm{~g}$ & $0.4 \mathrm{~g}$ & $0.4 \mathrm{~g}$ \\
\hline Formaldehyde & $1 \mathrm{ml}$ & $0.62 \mathrm{ml}$ & $1 \mathrm{ml}$ & $1 \mathrm{ml}$ \\
\hline Agar-agar & $8 g$ & $6 g$ & $6 g$ & $6 g$ \\
\hline Distilled water & $425 \mathrm{ml}$ & $250 \mathrm{ml}$ & $390 \mathrm{ml}$ & $390 \mathrm{ml}$ \\
\hline
\end{tabular}

Diet A=Varma et al.,(1975); Diet B=Mehta and David (1978); Diet C= Kanta and Sajjan (1989); Diet D= modified diet C; Diet $\mathrm{E}=$ natural food (sugarcane cuttings)

Table 2. Influence of different diets on adult emergence, adult longevity and sex ratio of sugarcane stalk borer, C. auricilius.

\begin{tabular}{|c|c|c|c|c|c|c|c|c|c|c|}
\hline \multirow[t]{3}{*}{ Diets } & \multicolumn{3}{|c|}{ Adult emergence (\%) } & \multicolumn{3}{|c|}{ Adult longevity (days) } & \multicolumn{4}{|c|}{ Sex ratio } \\
\hline & \multirow{2}{*}{$\begin{array}{c}\text { Ist } \\
\text { genera- } \\
\text { tion }\end{array}$} & \multirow{2}{*}{$\begin{array}{c}\text { IInd } \\
\text { genera- } \\
\text { tion }\end{array}$} & \multirow[t]{2}{*}{ Mean } & \multirow[t]{2}{*}{$\begin{array}{c}\text { Ist } \\
\text { generation }\end{array}$} & \multirow[t]{2}{*}{$\begin{array}{c}\text { IInd } \\
\text { generation }\end{array}$} & \multirow[t]{2}{*}{ Mean } & \multicolumn{2}{|c|}{$\begin{array}{c}\text { Ist } \\
\text { genera-tion }\end{array}$} & \multicolumn{2}{|c|}{$\begin{array}{c}\text { IInd } \\
\text { generation }\end{array}$} \\
\hline & & & & & & & $\mathbf{M}$ & $\mathbf{F}$ & $\mathbf{M}$ & $\mathbf{F}$ \\
\hline $\mathrm{A}$ & 80.46 & 80.86 & 80.66 & 4.45 & 4.14 & 4.29 & 1 & 0.8 & 1 & 1.16 \\
\hline $\mathrm{C}$ & 80.09 & 78.41 & 79.25 & 4.23 & 3.93 & 4.08 & 1 & 0.93 & 1 & 1 \\
\hline $\mathrm{D}$ & 77.78 & 77.53 & 77.65 & 3.42 & 3.29 & 3.35 & 1 & 0.98 & 1 & 0.88 \\
\hline $\mathrm{E}$ & 76.47 & 77.81 & 77.14 & 4.31 & 4.13 & 4.22 & 1 & 1.1 & 1 & 0.9 \\
\hline $\begin{array}{l}\text { S.E. (m) } \\
\pm\end{array}$ & 7.76 & 14.43 & 10.26 & 0.22 & 0.20 & 0.21 & - & - & - & - \\
\hline $\begin{array}{l}C D \\
(p=0.05)\end{array}$ & NS & NS & NS & 0.57 & 0.53 & 0.37 & - & - & - & - \\
\hline
\end{tabular}

Diet B could not be evaluated as C. auricilius could not accept the diet B to complete larval period, showing 100 per cent mortality

value of egg viability was recorded at diet A (216.25), followed by diet C (208.74), whereas mean fecundity was lower and on par on diets D (204.22) and E (203.62). It showed that diet A followed by diet C proved better than diets $\mathrm{D}$ and $\mathrm{E}$ with respect to egg viability.

Taking into account the cost of ingredients of the diets, the cost of production of $C$. auricilius was worked out. From the table 3, it was revealed the cost calculated for the diet A, C, D and $\mathrm{E}$ was found to be 103.43, 48.62, 48.32 and 166.67 , respectively. From these results, it was inferred that the cost of $\operatorname{diet} \mathrm{C}$ and $\mathrm{D}$ was lesser than $\operatorname{diet} \mathrm{A}$ and diet $\mathrm{E}$. Further, table also showed that the fecundity was found to be more on diets A and C than diets $\mathrm{D}$ and $\mathrm{E}$. The table 3 also indicated that the diet A ( similar to diet C) produced comparatively more viable eggs as compared to the diets $\mathrm{D}$ and $\mathrm{E}$, though it cost high. Therefore, diets $\mathrm{A}$ and $\mathrm{C}$ found to be more superior to $\mathrm{D}$ and $\mathrm{E}$ in producing $C$. auricilius in the laboratory.

Similar finding on diet A without any adverse effects on the biological attributes have also been reported by Varma et al. (1975) for rearing of sugarcane stalk borer, C. auricilius under laboratory conditions. Kanta and Sajjan (1989) using diet C have also successfully reared maize borer, Chilo partellus under invitro 
Table 3. Influence of various diets on fecundity and egg viability of sugarcane stalk borer, C. auricilius and their economics.

\begin{tabular}{|c|c|c|c|c|c|c|c|}
\hline \multirow[t]{2}{*}{ Diets } & \multicolumn{3}{|c|}{$\begin{array}{c}\text { Fecundity (average no. of eggs laid/ } \\
\text { female) }\end{array}$} & \multicolumn{3}{|c|}{ Egg viability (no. of viable eggs) } & \multirow{2}{*}{$\begin{array}{c}\text { Cost of diet } \\
\text { (one set) } \\
\text { (Rs.) }\end{array}$} \\
\hline & $\begin{array}{c}\mathbf{I}^{\text {st }} \\
\text { generation }\end{array}$ & $\begin{array}{c}\text { II }^{\text {nd }} \\
\text { generation }\end{array}$ & Mean & $\begin{array}{c}\mathbf{I}^{\text {st }} \\
\text { generation }\end{array}$ & $\begin{array}{c}\text { II }^{\text {nd }} \\
\text { generation }\end{array}$ & Mean & \\
\hline A & 235.12 & 231.79 & 233.45 & 217.43 & 215.08 & 216.25 & 103.43 \\
\hline $\mathrm{C}$ & 222.37 & 229.60 & 225.98 & 207.51 & 209.98 & 208.74 & 48.62 \\
\hline $\mathrm{D}$ & 216.15 & 220.58 & 218.36 & 202.92 & 205.52 & 204.22 & 48.32 \\
\hline $\mathrm{E}$ & 219.05 & 221.07 & 220.06 & 203.12 & 204.12 & 203.62 & 166.67 \\
\hline S.E. $(m) \pm$ & 27.06 & 16.67 & 25.83 & 32.37 & 15.53 & 23.10 & - \\
\hline $\mathrm{CD}(\mathrm{p}=0.05)$ & 6.26 & 4.92 & 4.18 & 6.85 & 4.74 & 3.95 & - \\
\hline
\end{tabular}

Diet B could not be evaluated as $C$. auricilius could not accept the diet to complete larval period, showing 100 per cent mortality

condition. Regarding cost analysis different artificial diets have been developed for Chilo sp. with lesser cost as compare to their natural food. Han et al (2012) developed soybean, Glycine max powder and fresh water bamboo, Zizania caduciflora based artificial diet for rearing of Chilo suppressalis. Furthermore, Ballal et al. (1995) reared successfully $C$. partellus on chickpea flour and maize leaf powder based artificial diet with lower cost than the natural food (maize).

\section{Conclusion}

It can be concluded from the above finding that rearing of $C$. auricilius on the artificial diets, $\mathrm{A}$ and $\mathrm{C}$ have shown the maximum adult emergence, longer adult longevity, highest fecundity, viability of egg and also these diets favoured the emergence of more number of females than males during development. Taking into account the economics, the diets $\mathrm{A}$ and $\mathrm{C}$ were found comparatively cheaper than the natural food (sugarcane). As these diets can be prepared with the easy availability of materials in the markets regardless of seasons it hastens rearing of larvae in large scale uninterruptedly in short space and time. Therefore the diets $\mathrm{A}$ and $\mathrm{C}$ can be used as an alternate diet next to natural diets i.e., sugarcane for mass rearing of $C$. auricilius invitro.

\section{REFERENCES}

Ballal, C.R., Pradyumn, K. and Ramani, S. (1995). Laboratory evaluation, storability and economics of an artificial diet for rearing Chilo partellus (Swinhoe) (Lepidoptera: Pyralidae). Journal of Entomological Research, 19: 135 $-141$.

Brar, K.S., Singh, D., Shenhmar, M. and Singh, J. (2001). Demonstration of the effectiveness of Trichogramma chilonis Ishii for the control of Chilo auricilius Dudgeon on sugarcane in the Punjab.In Symposium Biological Based Pest Managememt for Quality Crop Protection Current Millennium, Punjab Agricultural University, Ludhiana, pp 160-161.
Chaudhary, J.P., Bhardwaj, S.C. and Gupta, J.N. (1980). Failure of insecticidal sprays for the control of stalk borer, Chilo auricilius Ddgn. Indian Journal of Agricultural Research, 14: 22-28.

Cheema, H.S. and Singh, B. (1990). A computer programs for the analysis of commonly used experimental designs. pp. 7-13. Punjab Agricultural University, Ludhiana

David, H. and Nandgopal, V. (1986). Pests of sugarcane, distribution, symptomology of attack and identification, In: David, H., Easwaramoorthy, S. and Jayanthi, R. (eds) Sugarcane Entomology in India. pp 1-29. ICAR Publication, Coimbatore, India.

Doomra, S. (1992). Biological control of sugarcane stalk borer, Chilo auricilius Dudgeon in Nawanshahr sugar mills area. In: Proceedings of the National Symposium on Recent advances in Integrated Pest Management. Punjab Agricultural University, Ludhiana. pp 72.

Han, L., Li, S., Liu, P., Peng, Y. and Hou, M. (2012). New artificial diet for continuous rearing of Chilo suppressalis (Lepidoptera: Crambidae). Annual Entomological Society of America, 105: 253-258.

Kanta, U. and Sajjan, S.S. (1989). Formulation of an improved artificial diet for the mass rearing of Chilo partellus (Swin). Journal of Insect Science, 2: 98-102.

Mehta, U.K. and David, H. (1978). A laboratory technique for rearing the sugarcane internode borer, Chilo indicus K. on an artificial medium. Indian Sugar, 28: 263-66.

Misra, M.P., Pawar, A.D. and Srivastava, U.L. (1986). Biocontrol of sugarcane moth borers by releasing Trichogramma parasites at Harinagar, West Champaran, Bihar. Indian Journal of Plant Protection, 14: 89-91.

Shenhmar, M., Brar, K.S. and Singh, J. (2005). Advances in Biocontrol of Sugarcane borers in Punjab.In: Geol S C (ed) Adv Indian Entomol: Productivity and Health. U.P. Zoological Society, Muzaffarnagar. pp 155-64.

Varma, A. and Avasthy, P.N. (1973). An artificial diet for the rearing of stalk borer, Chilo auricilius Dudg. Experentia, 29: 1161-1162.

Varma, A., Avasthy, P.N. and Srivastava, T.N. (1975). Laboratory rearing of sugarcane stalk borer, Chilo auricilius dudg. through successive generations. Indian Sugar, 15: 1-4. 